Elsevier required licence: (c) 2018. This manuscript version is made available under the CC-BY-NC-ND 4.0 license http://creativecommons.org/licenses/by-nc-nd/4.0/ 


\title{
Assessment of microbial products in the biosorption process of Cu(II) onto aerobic granular sludge: Extracellular polymeric substances contribution and soluble microbial products release
}

\author{
Linxian Huang ${ }^{\text {a }}$, Meilin Li ${ }^{\text {a }}$, Guangchao Si ${ }^{\text {a }}$, Jinglin Wei ${ }^{\text {a }}$, Huu Hao Ngo ${ }^{\text {b }}$, Wenshan Guo ${ }^{\text {b }}$ \\ Weiying $\mathrm{Xu}{ }^{\mathrm{a}}$, Bin $\mathrm{Du}{ }^{\mathrm{a}}$, Qin Wei ${ }^{\mathrm{c}}$, DongWei ${ }^{\mathrm{a}, *}$ \\ ${ }^{a}$ School of Resources and Environment, University of Jinan, Jinan 250022, PR China \\ ${ }^{b}$ School of Civil and Environmental Engineering, University of Technology Sydney, Broadway, NSW \\ 2007, Australia \\ ${ }^{c}$ Key Laboratory of Interfacial Reaction \& Sensing Analysis in Universities of Shandong, School of \\ Chemistry and Chemical Engineering, University of Jinan, Jinan 250022, PR China \\ *Corresponding author. E-mail address: weidong506@163.com (D. Wei).
}

\begin{abstract}
In the present study, the responses of microbial products in the biosorption process of $\mathrm{Cu}$ (II) onto aerobic granular sludge were evaluated by using batch and spectroscopic approaches. Batch experimental data showed that extracellular polymeric substances (EPSs) contributed to $\mathrm{Cu}$ (II) removal from an aqueous solution, especially when treating low metal concentrations, whereas soluble microbial products (SMPs) were released under the metal stress during biosorption process. A three-dimensional excitation-emission matrix (3D-EEM) identified four main fluorescence peaks in the EPS, i.e., tryptophan protein-like, aromatic protein-like, humic-like and fulvic acidlike substances, and their fluorescence intensities decreased gradually in the presence of $\mathrm{Cu}$ (II) during the sorption process. Particularly, tryptophan protein-like substances quenched the $\mathrm{Cu}(\mathrm{II})$ binding to a much higher extent through a static quenching process with less than one class of binding sites. According to the synchronous fluorescence spectra, the whole fluorescence intensity of released SMP samples expressed an increased trend with different degrees along with contact time. Two-dimensional correlation spectroscopy (2D-COS) suggested that the fulvic-like fluorescence fraction might be more susceptible to metal exposure than other fractions. The result of molecular weight distribution demonstrated that the SMPs released from the biosorption process differed significantly according to contact time. The result obtained could provide new insights into the responses of microbial products from aerobic granular sludge with heavy metal treatment.
\end{abstract}

Keywords: Aerobic granular sludge; Extracellular polymeric substances (EPSs); Soluble microbial products (SMPs); Heavy metal; Biosorption

\section{Introduction}

With the rapid development of population growth and industrialization worldwide, heavy metal pollution is of specific concern due to its toxicity, bioaccumulation tendency and persistence in nature [1]. In recent years, a great number of heavy metals are generated from many industries such as tanning, battery preparation, mining, surface finishing, energy and fuel production, electric appliance manufacturing, etc., and these industries create serious environmental pollution, threatening human health [2] ; [3]. Due to the non-biodegradability of heavy metals, wastewater 
containing heavy metals is often pre-treated by various physicochemical processes, including chemical precipitation, ion exchange, membrane separation, reverse osmosis and sorption [4].

Among these pretreatments, sorption is regarded as one of most cost-effective and environmentfriendly technologies for removal or recovery of heavy metal ions from aqueous solutions [5] ; [6]. Until the present, various low-cost biosorbents have been developed by utilization of bacteria, waste sludge, bioflocs, biomass, fungi, etc. [7] ; [8]. Compared to activated sludge, aerobic granular sludge has the advantages of a denser microbial structure and better settling capacity, meaning that aerobic granular sludge could easily be separated from the aqueous environment after metal pollutant treatment [9] ; [10]. Therefore, aerobic granular sludge as a promising biosorbent has been applied successfully for treating various toxic chemicals in wastewater [11]; [12].

Specifically, microbial products, including extracellular polymeric substances (EPSs) and soluble microbial products (SMPs, or soluble EPSs), are excreted by sludge microorganisms due to the metabolic activity of bacterial cultures during their growth, decay or in a response to environmental conditions in wastewater treatment systems [13]. EPSs are located at or outside the cell surface, while SMPs are the soluble cellular polymeric components dissolved in aqueous solution, irrespective of their origins [14]. EPSs are well-known to play a significant role in affecting the physicochemical properties of aerobic granular sludge, including structure, stability, deposition, retention, flocculation, settling, dewatering, and biofouling [15] ; [16]. Specifically, EPSs have been extensively applied as an effective adsorbent for treating heavy metal from wastewater because of their abundant functional groups and binding sites [17]. Therefore, the presence of EPSs in aerobic granular sludge is considered beneficial for migration and removal of heavy metals through a complexation process [18].

Although EPSs contribute to remove heavy metal from aqueous solution, SMPs may be released from microorganisms as by-products under the stress of toxic compounds during the sorption process. SMPs are generally accepted to be composed of hydrolysis products of EPSs and decay products of active cells, which are the major components of soluble organic matter in the effluents from wastewater treatment plants [19]. Hence, the release of SMPs from aerobic granular sludge under conditions of heavy metal exposure may negatively affect the quality of the biosorptiontreated effluent [14]. However, to the best of our knowledge, limited information is available about the production of SMPs in the biosorption process of heavy metal onto aerobic granular sludge. Therefore, it is essential to study SMP release in-depth, not only in terms of improving the comprehension of the sludge-based biosorption process but also providing possible information for reducing secondary pollution through the optimization of operational parameters.

Based on the above discussion, the objective of this study was to evaluate the role and characterization of microbial products in the biosorption process of heavy metal onto aerobic granular sludge by using batch and spectroscopic approaches. To achieve this purpose, a combined use of excitation-emission matrix (EEM), synchronous fluorescence spectra, two-dimensional correlation spectroscopy (2D-COS), and molecular weight (MW) distribution was employed to characterize the properties of EPSs and SMPs in the biosorption process. The result obtained could provide better understanding of the responses of microbial products of sludge-based biosorbents during the heavy metal treatment process. 


\section{Materials and methods}

\subsection{Aerobic granular sludge}

Aerobic granular sludge was obtained from our laboratory-scale sequencing batch reactor (SBR), which was operated for more than one year for treating high ammonia-nitrogen wastewater. The detailed composition of influent wastewaters could be found in the literature reported by Wei et al. [20]. The average size of the aerobic granular sludge used for sorption experiments was approximately $1.5 \mathrm{~mm}$. Before the sorption experiment, the aerobic granular sludge was collected at the end of the aeration process and washed three times using deionized water to remove the surface-soluble ions.

\subsection{Batch sorption experiments}

In the present study, all chemicals were of analytical-reagent grade and purchased from Sinopharm Chemical Reagent Co., Ltd. (Shanghai, China) without further purification. $\mathrm{Cu}$ (II) was selected as a target for biosorption onto aerobic granular sludge from the view point of sorption kinetics and sorption isotherms. Detailed biosorption kinetics experiments were carried out in a $250-\mathrm{mL}$ Erlenmeyer bottle containing approximately $0.25 \mathrm{~g}$ (dry weight) of aerobic granular sludge and $100 \mathrm{~mL}$ of $\mathrm{Cu}(\mathrm{II})$ solution $(100 \mathrm{mg} / \mathrm{L})$ at $25^{\circ} \mathrm{C}$. The initial $\mathrm{pH}$ of the mixed solution was adjusted to 5.0 by using $0.1 \mathrm{~mol} / \mathrm{L} \mathrm{HCl}$ and $\mathrm{NaOH}$ to avoid precipitation. The samples were taken at different time intervals in the range of 0-360 min. The adsorption isotherm experiment was carried out with different initial concentrations of $\mathrm{Cu}$ (II) from 25 to $1200 \mathrm{mg} / \mathrm{L}$ for $5 \mathrm{~h}$ to ensure equilibrium at $25^{\circ} \mathrm{C}$.

After the batch sorption experiments, the mixed solution was first centrifuged at $5000 \mathrm{rpm}$ for $10 \mathrm{~min}$, and the $\mathrm{Cu}$ (II) concentration in the supernatant was measured to obtain the amount of $\mathrm{Cu}$ (II) sorbed onto the aerobic granular sludge. Then, the remaining aerobic granular sludge was used to extract EPSs, and the $\mathrm{Cu}$ (II) analyzed in the extracted EPS solution was recognized as $\mathrm{Cu}$ (II) adsorbed by EPSs. The $\mathrm{Cu}$ (II) adsorbed by sludge could be obtained by subtracting the amount absorbed by EPS from the total adsorption of aerobic granular sludge, as similarly reported by Xu et al. [21].

\subsection{Fluorescence spectra}

EPS and SMP samples were extracted at various reaction times during biosorption kinetics experiments. More detailed EPS samples were extracted using a heating method, and the detailed procedure could be found in the literature reported by Li and Yang [22]. The 3D-EEM spectra were collected with subsequent scanning emission spectra from 280 to $550 \mathrm{~nm}$ at $0.5 \mathrm{~nm}$ increments by varying the excitation wavelength from 200 to $400 \mathrm{~nm}$ in $10 \mathrm{~nm}$ increments. The width of the excitation/emission slit was set to $5.0 \mathrm{~nm}$, and the scanning speed was set to $1200 \mathrm{~nm} / \mathrm{min}$ for all the fluorescence measurements.

Fluorescence quenching titration of EPSs by $\mathrm{Cu}(\mathrm{II})$ was further used to evaluate the mechanism of the interaction between them through synchronous fluorescence spectra. More detailed, $5 \mathrm{~mL}$ EPS and different volumes of pre-determined $\mathrm{Cu}(\mathrm{II})$ solution were successively added into a $10 \mathrm{~mL}$ 
centrifuge tube to ensure a $\mathrm{pH}$ of 5.0. The final $\mathrm{Cu}$ (II) concentrations in the mixed solution were varied from 0 to $200 \mathrm{mg} / \mathrm{L}$. Next, the mixed solution was balanced for $4 \mathrm{~h}$ at room temperature to ensure sorption equilibrium. Then, synchronous fluorescence spectra were recorded from 240 to $350 \mathrm{~nm}$ with $\Delta \lambda$ at $60 \mathrm{~nm}$.

\subsection{Synchronous fluorescence coupled with $2 D-C O S$}

$\mathrm{The} \mathrm{Cu}$ (II) concentration was analyzed using an atomic absorption spectrometer (GFA-7000, Shimadzu Co., Kyoto, Japan). The data were analyzed in triplicate, and the averaged data are presented here. The experimental error of the results was within $\pm 5 \%$. The molecular weight distribution of the SMP samples was measured using a high-performance liquid chromatography system (Waters 1525, Waters, USA). The 2D-COS was applied in this study according to the method reported by Noda [23].

$$
\begin{aligned}
& \Phi\left(x_{1}, x_{2}\right)=\frac{1}{T_{\max }-T_{\min }} \int_{T}^{T_{\max }} \tilde{\mathrm{y}}\left(x_{1}, t\right) \cdot \tilde{\mathrm{y}}\left(x_{1}, t\right) \mathrm{d} t \\
& \Psi\left(x_{1}, x_{2}\right)=\frac{1}{T_{\max }-T_{\min }} \int_{T}^{T_{\max }} \tilde{\mathrm{y}}\left(x_{1}, t\right) \cdot \tilde{z}\left(\left(x_{2}, t\right) \mathrm{d} t\right)
\end{aligned}
$$

where $x$ and $t$ are a spectral variable (i.e., wavelength) and an external perturbation, respectively. $\tilde{y}\left(x_{1}, t\right)$ is the dynamic spectrum, and $\tilde{z}\left(x_{2}, t\right)$ is the Hilbert-transformed orthogonal spectrum.

\section{Results and discussion}

\subsection{Contact time on EPS contribution to Cu(II) removal}

Fig. 1 shows the effect of contact time on $\mathrm{Cu}(\mathrm{II})$ sorption onto aerobic granular sludge, including the removal efficiencies caused by EPS as well as residual sludge. $\mathrm{Cu}$ (II) sorption onto aerobic granular sludge was found to occur in two steps as a function of contact time. The rapid metal sorption was completed within the initial $30 \mathrm{~min}$, followed by a much slower uptake step for the next $330 \mathrm{~min}$, with the total metal removal efficiencies of $93.6 \%$ and $96.5 \%$, respectively. Specifically, $\mathrm{Cu}$ (II) binding to EPS had a relatively quicker sorption equilibrium time (15 min) than residual sludge (120 $\mathrm{min})$, suggesting that the EPSs played a significant role in the initial sorption process. Detailed $\mathrm{Cu}(\mathrm{II})$ adsorbed by EPS accounted for $13.3 \%$ of the total removal efficiency within the initial $30 \mathrm{~min}$, while the corresponding value decreased to approximately $11.6 \%$ at the end of the equilibration time. The decreased percentage of EPS removal of metal may be attributed to the increased sludge sorption in the slower uptake step.

\subsection{Sorption isotherm}

In present study, two common sorption isotherms of Langmuir and Freundlich models were used to fit $\mathrm{Cu}$ (II) sorption onto aerobic granular sludge in the presence and absence of EPSs, as shown in Fig. 2. Table S1 summarizes the constants and correlation coefficients of the adsorption isotherms for the adsorption of $\mathrm{Cu}(\mathrm{II})$ onto aerobic granular sludge. The sorption isotherms are fitted better by the Langmuir model than by the Freundlich model in spite of the presence and absence of EPSs, suggesting that $\mathrm{Cu}$ (II) sorption onto aerobic granular sludge is monolayer 
coverage. $\mathrm{Li}$ et al. [24] also observed that $\mathrm{Cu}(\mathrm{II})$ sorption onto $\mathrm{Fe}_{2} \mathrm{O}_{3}\left(\mathrm{P}-\mathrm{Fe}_{2} \mathrm{O}_{3}\right)$ microcubes was better fitted to the Langmuir model porous. The calculated maximum adsorption capacity $\left(q_{\mathrm{m}}\right)$ from the Langmuir model is $123.2 \mathrm{mg} / \mathrm{g}$ for aerobic granular sludge (Table S1), suggesting excellent adsorption capacity of granular sludge-based biosorbent for $\mathrm{Cu}$ (II) for application. The $q_{\mathrm{m}}$ of the aerobic granular sludge was like the observation of $\mathrm{Cu}(\mathrm{II})$ sorption onto $\mathrm{Ca} / \mathrm{Al}$-layered double hydroxides (CA-LDH) after graphene oxide (GO) coagulation $(122.7 \mathrm{mg} / \mathrm{g})[25]$.

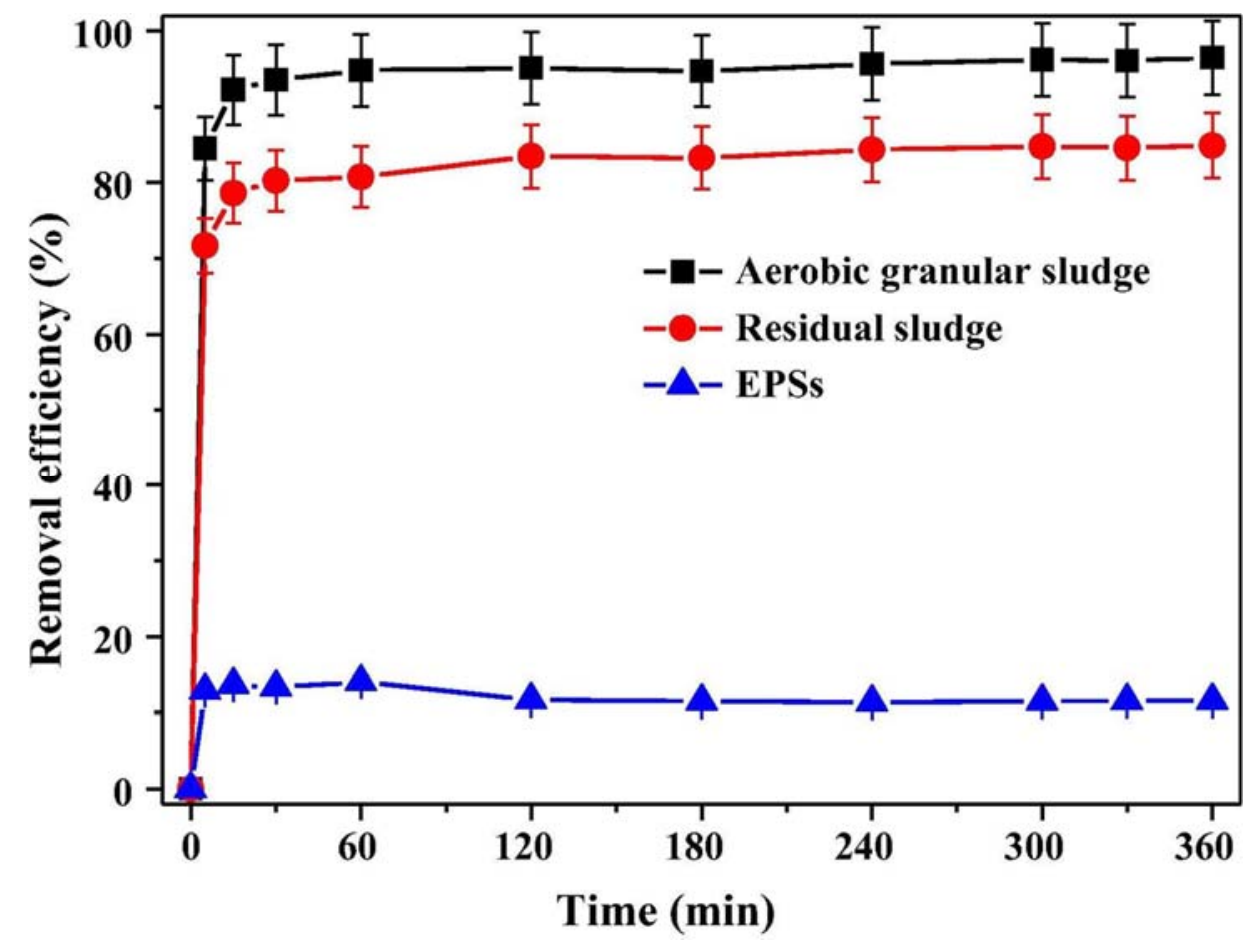

Fig. 1. Effect of contact time on $\mathrm{Cu}$ (II) sorption onto aerobic granular sludge

Additionally, we conclude from Fig. 2B that EPS sorption for metal migration was significantly different at low and high influent metal concentrations. Specifically, EPS sorption contributed to $82.85 \%$ of total $\mathrm{Cu}$ (II) removal with an initial $\mathrm{Cu}$ (II) concentration of $25 \mathrm{mg} / \mathrm{L}$, whereas this percentage decreased to only $16.2 \%$ at a $\mathrm{Cu}(\mathrm{II})$ concentration of $400 \mathrm{mg} / \mathrm{L}$. Hence, EPSs may be more important as a useful reservoir to protect the sludge microorganisms in the case of low concentrations of toxic substances. Moreover, the value of the maximum adsorption capacity $\left(q_{\mathrm{m}}\right)$ was $114.01 \mathrm{mg} / \mathrm{g}$ of aerobic granular sludge in the absence of EPSs (Fig. 2A), implying that $\mathrm{Cu}$ (II) binding to EPS contributed $7.49 \%$ of total $\mathrm{Cu}$ (II) removal at equilibrium.

\subsection{Binding property and mechanism between EPS and Cu(II)}

Fig. 3 shows the 3D-EEM of EPS samples before and after binding to $\mathrm{Cu}(\mathrm{II})$ at various reaction times (0-360 min) during the sorption process. Table S2 summarizes the detailed fluorescence spectral parameters of EPS, including fluorescence intensity and peak location. As shown in Fig. $3 \mathrm{~A}$, four main fluorescence peaks (Peaks A, B, C and D) were identified from the raw EPS in the absence of $\mathrm{Cu}$ (II). Peak A and Peak B were located at Ex/Em of 290/367 and 220/364 nm, respectively, corresponding to the presence of tryptophan PN-like substances and aromatic PN-like substances [26]. A broad peak was identified at Ex/Em of 350/444.5 nm (Peak C), suggesting the presence of humic-like substances [27]. Peak D presented a fluorescence peak at Ex/Em of 
280/432 nm, indicating the presence of fulvic acid-like substances [28]. As contact time increased, not only fluorescence intensity but also fluorescence location in four EPS samples changed to different degrees. The intensity of Peak A decreased to a much higher extent (731.1-126.9 a.u.) than the intensity of the peaks from other substances, suggesting that tryptophan PN-like substances played a significant role in the $\mathrm{Cu}(\mathrm{II})$ binding during sorption process.
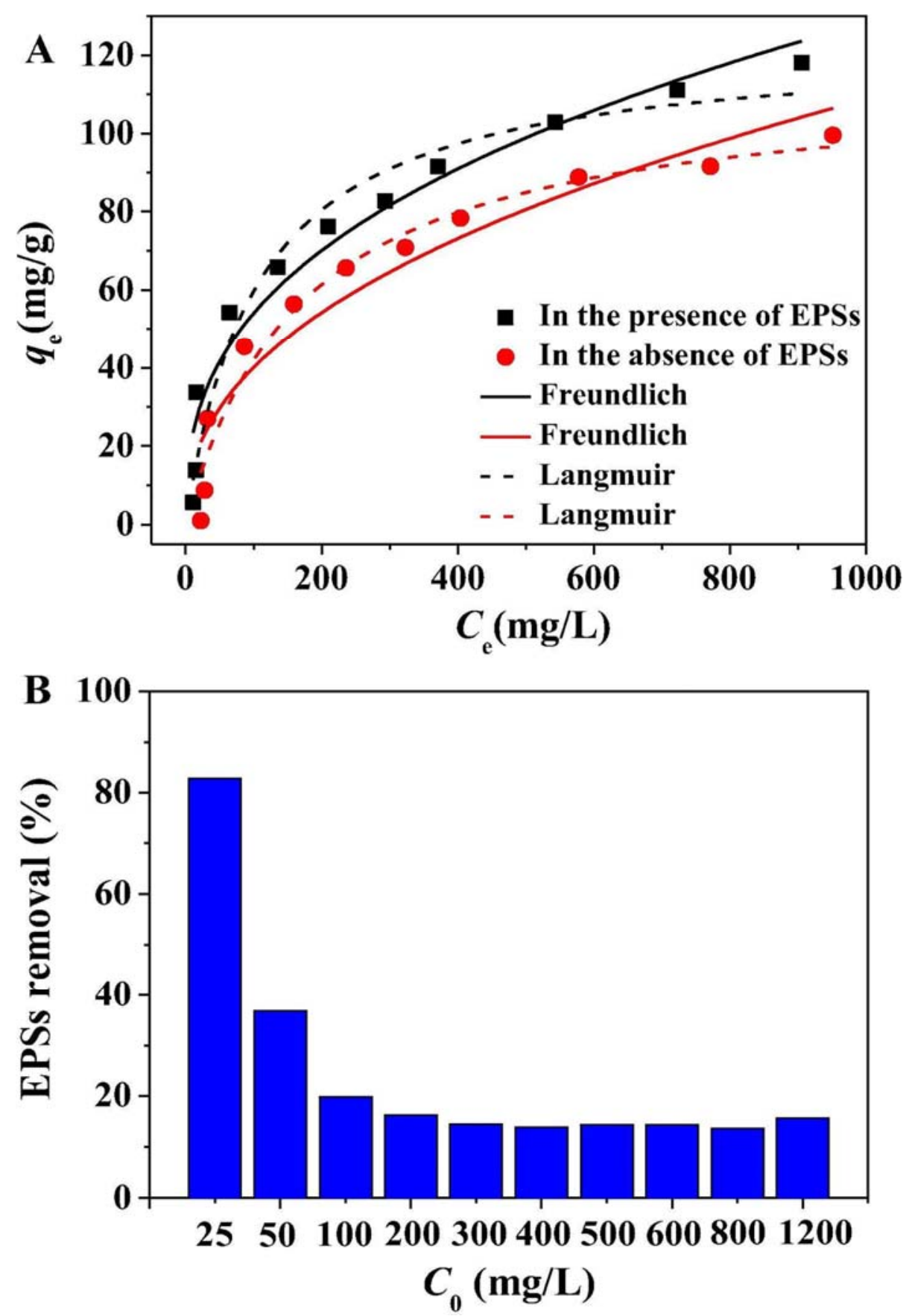

Fig. 2. (A) Langmuir and Freundlich adsorption isotherms fit of $\mathrm{Cu}(\mathrm{II})$ sorption onto aerobic granular sludge in the presence and absence of EPSs; (B) EPSs removal contributions at various $\mathrm{Cu}$ (II) concentrations from adsorption isotherm. 

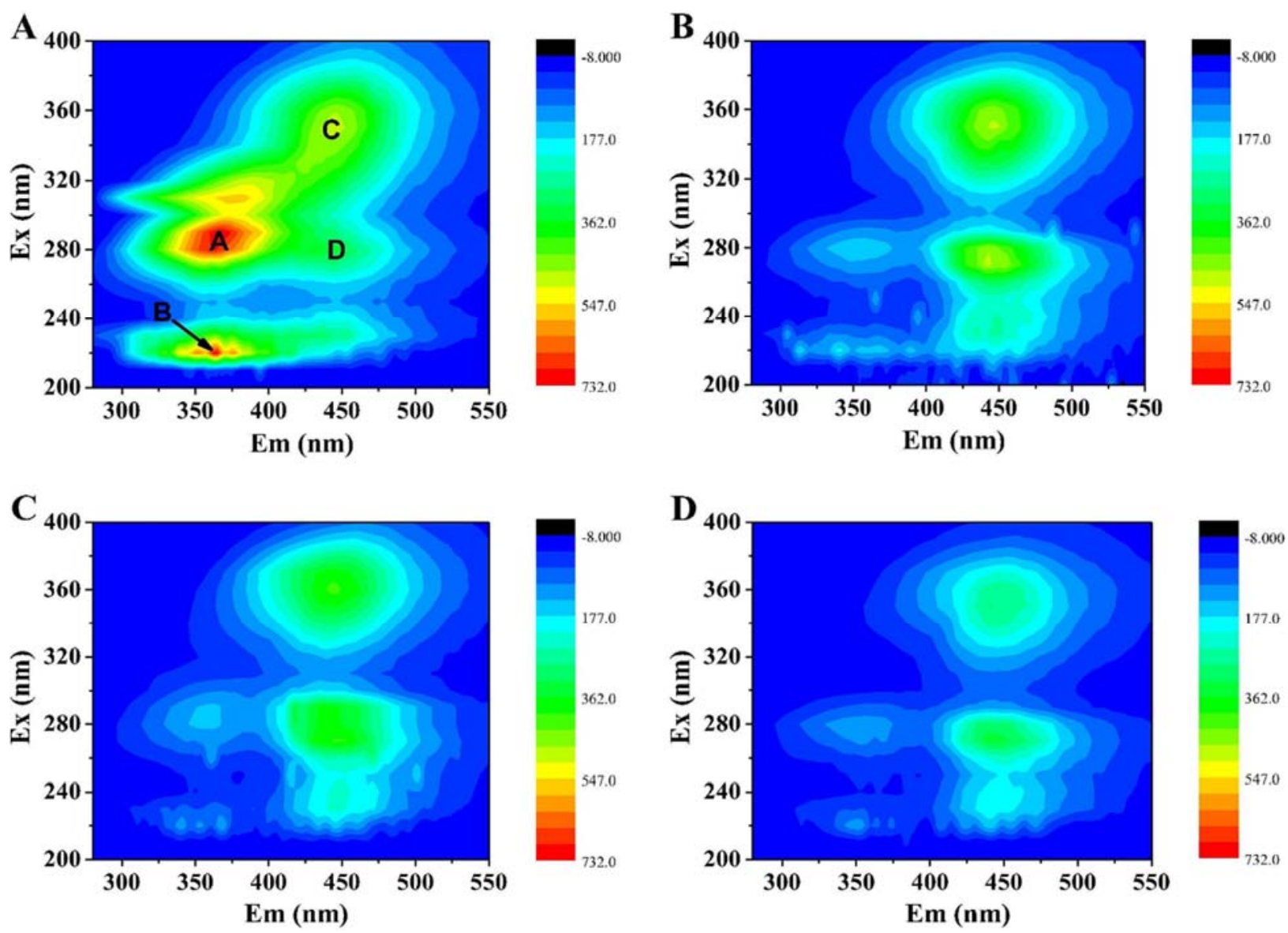

Fig. 3. 3D-EEM of EPSs samples before and after binding to $\mathrm{Cu}(\mathrm{II})$ at various reaction times during the sorption process: (A) $0 \mathrm{~min}$; (B) $45 \mathrm{~min}$; (C) $240 \mathrm{~min}$; (D) $360 \mathrm{~min}$.

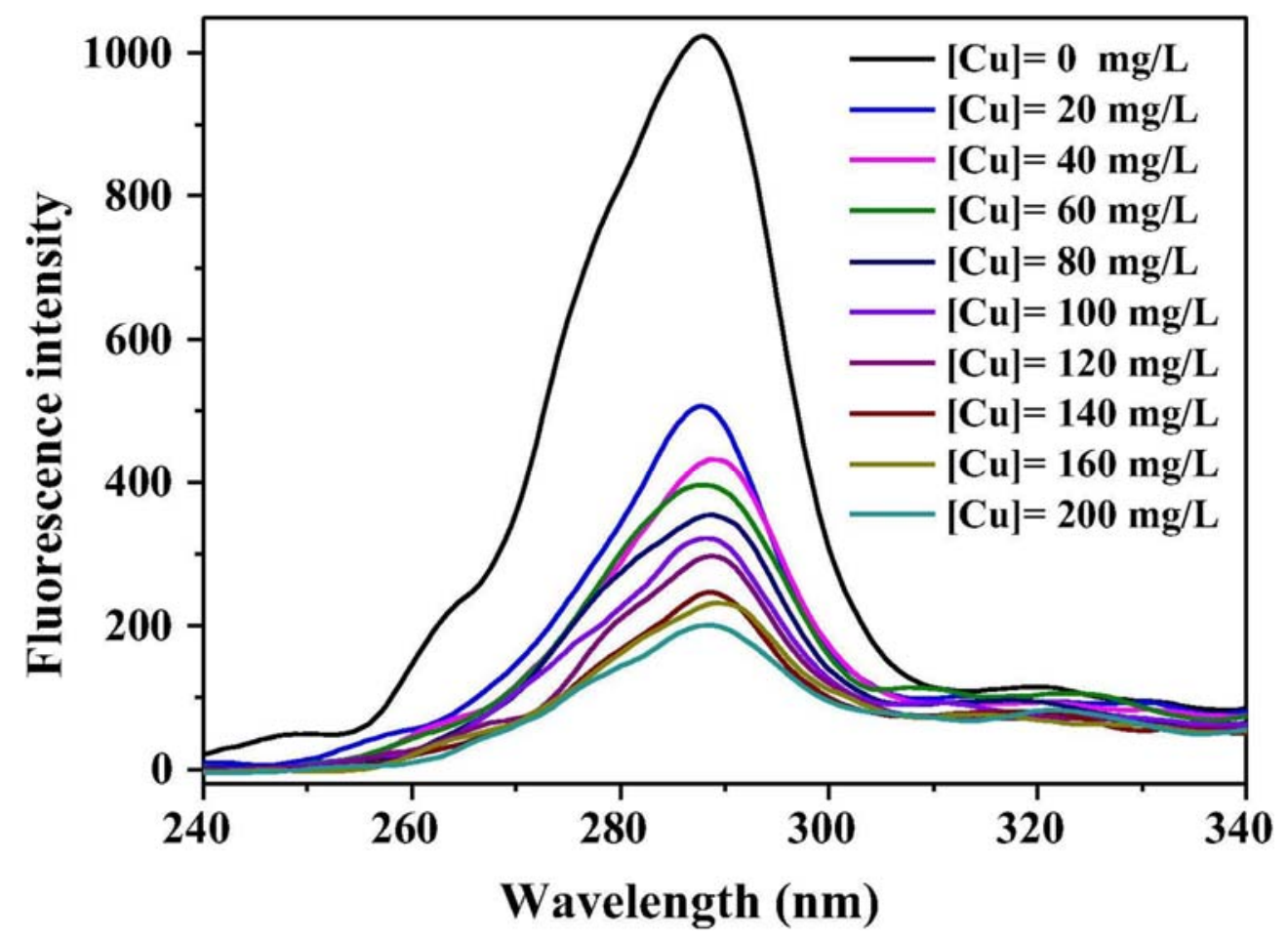

Fig. 4. Synchronous fluorescence spectra of the interaction between EPSs and $\mathrm{Cu}(\mathrm{II})$. 
To confirm the binding mechanism between tryptophan PN-like substances and $\mathrm{Cu}(\mathrm{II})$, synchronous fluorescence spectra were further applied to evaluate their interaction process at the molecular level. As shown in Fig. 4, a remarkable fluorescence peak was observed at $288 \mathrm{~nm}$ with fixed $\Delta \lambda$ at $60 \mathrm{~nm}$. The fluorescence intensity was found to be significantly quenched to the levels of $49.4 \%$ and $19.6 \%$ of the initial intensity of the raw EPSs when $\mathrm{Cu}$ (II) concentration increased from 20 to $200 \mathrm{mg} / \mathrm{L}$, respectively. The result clearly proved the strong interaction between tryptophan residues in EPS and heavy metals.

The modes of fluorescence quenching are mainly divided into static quenching and dynamic quenching [29]. The static mechanism is caused by ground-state complex formation between the fluorophores and the quencher, whereas the dynamic quenching results from diffusive encounter collisions in the excited-state [30]. To confirm the quenching mechanism, the fluorescence quenching data were further described by using the linear Stern-Volmer equation (3):

$\mathrm{F}_{0} / \mathrm{F}=1+\mathrm{K}_{\mathrm{sv}}[\mathrm{Cu}]=1+\mathrm{K}_{\mathrm{q}} \tau_{0}[\mathrm{Cu}]$

where $F_{0}$ and $F$ are the fluorescence intensities in the absence and presence of $\mathrm{Cu}(\mathrm{II})$, respectively; $K_{\mathrm{sv}}$ is the Stern-Volmer quenching rate constant; $K_{\mathrm{q}}$ is the biomolecular quenching rate constant; $\tau_{0} \tau 0$ is the average lifetime of the molecule in the absence of quencher $\left(10^{-8} \mathrm{~s}\right)$; and $[\mathrm{Cu}]$ is the $\mathrm{Cu}$ (II) concentration.

The Stern-Volmer plot of tryptophan PN-like substances with increased dosages of $\mathrm{Cu}(\mathrm{II})$ is presented in Fig. S1. The quenching rate constant of $K_{\mathrm{q}}$ for PN-like substances was calculated as $1.114 \times 10^{11} \mathrm{~L} / \mathrm{mol} / \mathrm{s}$, which was much greater than the maximum scatter collision quenching constant of the quencher to the biomacromolecule of $2.0 \times 10^{10} \mathrm{~L} / \mathrm{mol} / \mathrm{s}$. Therefore, the quenching between quencher and fluorescent substances was controlled mainly by a static quenching process from the formation of the EPS-Cu(II) complex rather than a dynamic quenching process.

For a binding involving a static quenching mechanism, the relationship between fluorescence quenching intensity and the concentration of quenchers can be described by the following equation (4):

$$
\log \frac{F_{0}-F}{F}=\log K_{a}+n \log [\mathrm{Cu}]
$$

where $K_{\mathrm{a}}$ is the binding constant, reflecting the degree of reaction between the tryptophan PN-like substance and $\mathrm{Cu}(\mathrm{II})$, and $n$ is the number of binding sites per EPS molecule, specifying the number of $\mathrm{Cu}$ (II) ions bound to a PN-like substance macromolecule. According to Fig. S2, the number of binding sites $(n)$ for between PN-like substances and $\mathrm{Cu}(\mathrm{II})$ was smaller than 1 (approximately 0.61), suggesting that less than one class of binding sites was present in the tryptophan PN-like substance.

\subsection{Smps released from biosorption process}

\subsubsection{EEM spectra}


Compared to 3D-EEM of the EPS samples, only two obvious fluorescence peaks (Peak C and Peak D) were identified from the released SMPs during the biosorption process at various reaction times ( 5 to $360 \mathrm{~min}$ ). As described in Fig. 5, both corresponding fluorescence intensities expressed increasing trends with contact time (up to 419.39 and 636.28 a.u., respectively). Evidently, humiclike substances (Peak C) with regard to a biological production and activity of microorganisms were representative of biodegradable substances, whereas fulvic acid-like substances could be referred to as non-biodegradable substances [26]. As shown in Table S3, the intensity ratio of Peak C/Peak D was consistently between 0.64 and 0.67 , suggesting the two kinds of released SMP components were relatively stable throughout the whole sorption process. A clear redshift in terms of emission wavelength was observed in Peak C, which may be attributed to the changed structure of the chemical substances that were responsible for fluorescent characteristics, such as carbonylcontaining substituents, hydroxyl, alkoxyl and amino groups shifting to longer wavelengths [31].
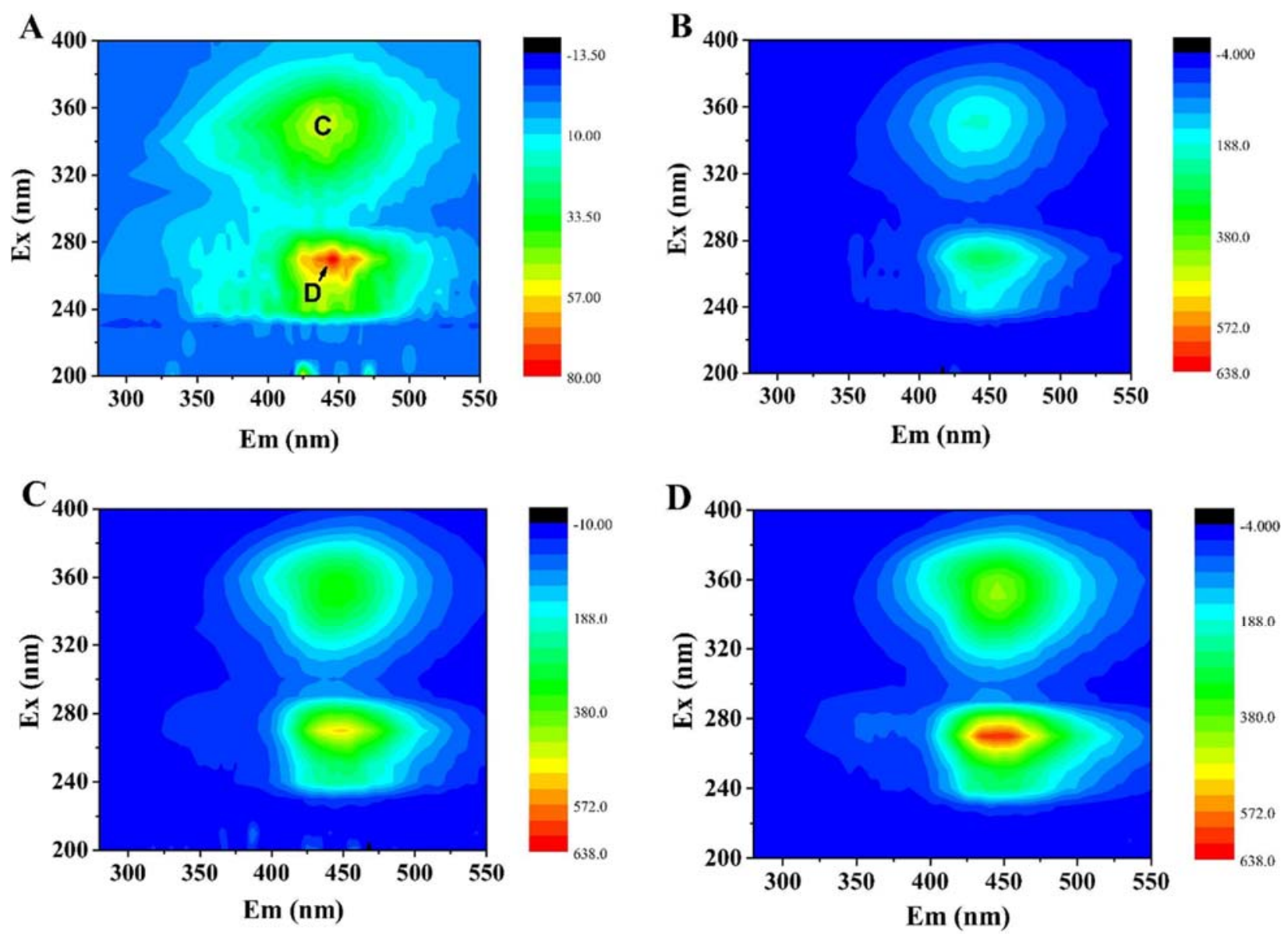

Fig. 5. 3D-EEM of SMPs release at various reaction times: (A) $5 \mathrm{~min}$; (B) $45 \mathrm{~min}$; (C) $240 \mathrm{~min}$; (D) $360 \mathrm{~min}$.

\subsubsection{Synchronous fluorescence spectra}

Fig. 6 shows the changes in synchronous fluorescence spectra of released SMP samples as a function of contact time. In the present study, three distinctive regions of synchronous spectra were assigned to protein-like, fulvic-like, and humic-like fluorescence fractions, corresponding to the wavelengths ranging from 250 to $300 \mathrm{~nm}, 300-380 \mathrm{~nm}$ and $380-550 \mathrm{~nm}$, respectively [32]. As presented in Fig. 6, the whole fluorescence intensity expressed an increased trend with different 
degrees along with contact time. A much higher peak at $370 \mathrm{~nm}$ was observed than the peaks at 275 and $460 \mathrm{~nm}$, implying that the fulvic-like fluorescence fraction was more sensitive to the addition of $\mathrm{Cu}(\mathrm{II})$. The result was consistent with the observation of 3D-EEM, suggesting that synchronous fluorescence spectra could constitute a useful method to assess the properties of released SMPs. Since the fluorescence intensity of SMP was time-dependent, the rapid adsorption for equilibrium may therefore be an effective strategy to reduce SMP release.

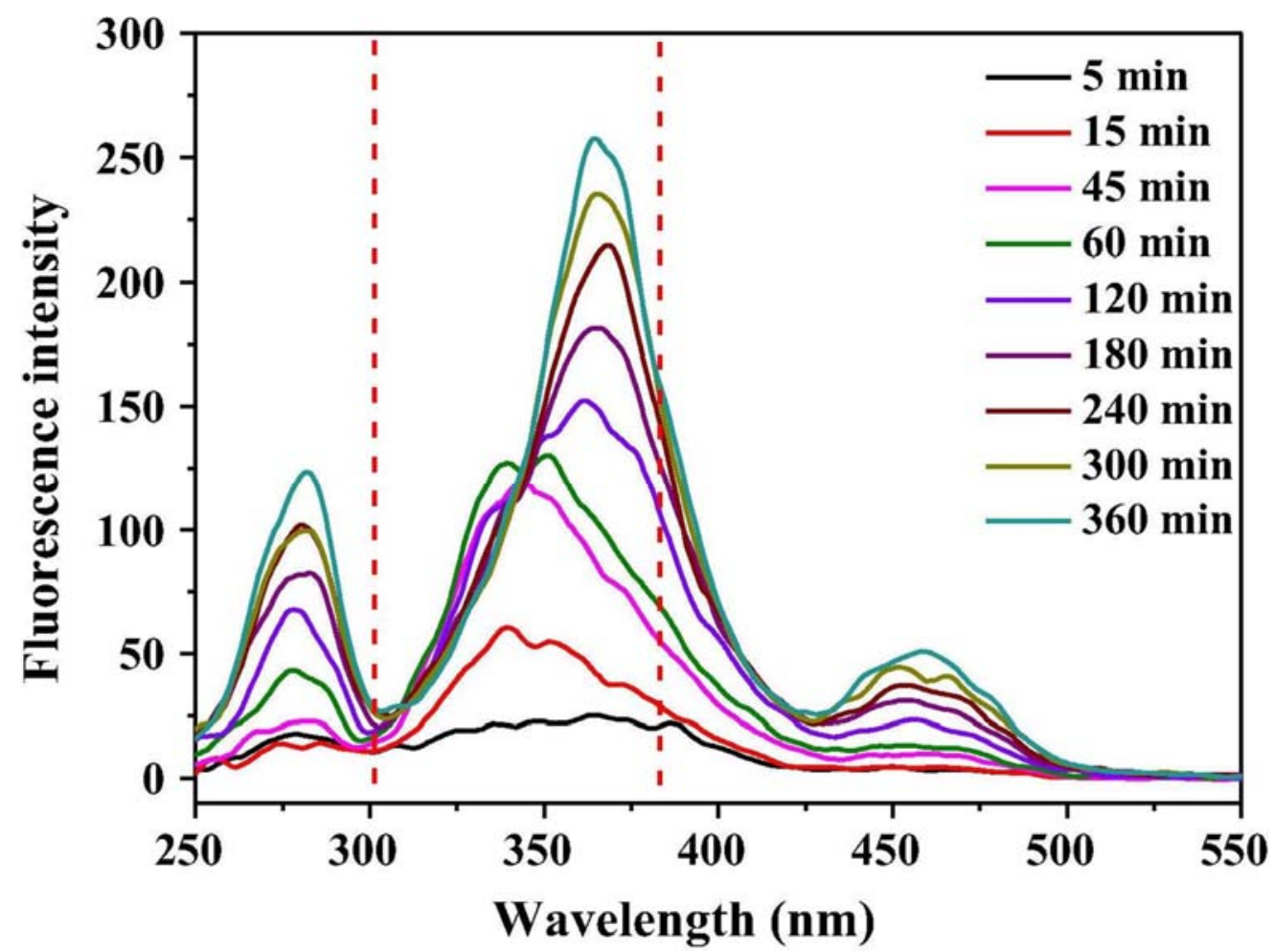

Fig. 6. Changes in synchronous fluorescence spectra of released SMPs as a function of contact time.

As a rapid, information-rich and nondestructive monitoring tool, synchronous fluorescence has been applied successfully to analyze the microenvironmental changes of chromophores in water and wastewater. Guo et al. [33] identified the main fractions of fluorescent dissolved organic matter (DOM) during wastewater treatment by using synchronous spectra. Li et al. [34] also investigated the characterization of SMPs in a partial nitrification sequencing batch biofilm reactor, suggesting that the protein-like fluorescence fraction was the main component in SMP. Lai et al. [35] estimated the biodegradability of treated sewage samples using synchronous fluorescence spectra, implying that fluorescence indices are expected to be utilized for development of real-time monitoring.

\subsubsection{D-COS}

To examine the potential existence of heterogeneous sites with respect to the time-dependent synchronous fluorescence spectra, 2D-COS was further applied to enhance the spectral resolution for exploring the detailed properties of released SMPs. As shown in Fig. 7A, the synchronous map displayed three positive auto-peaks centering at approximately 276, 360, and $455 \mathrm{~nm}$ along the diagonal line, indicating that the spectral changes took place in the same direction at the corresponding wavelength ranges, as similarly reported by $\mathrm{Xu}$ and Jiang [36]. Moreover, the 
intensities of auto-peaks in present study decreased in the following order: $367.5>281.5>455 \mathrm{~nm}$, suggesting that the fulvic-like fluorescence fraction might be more susceptible to metal exposure than other fractions.
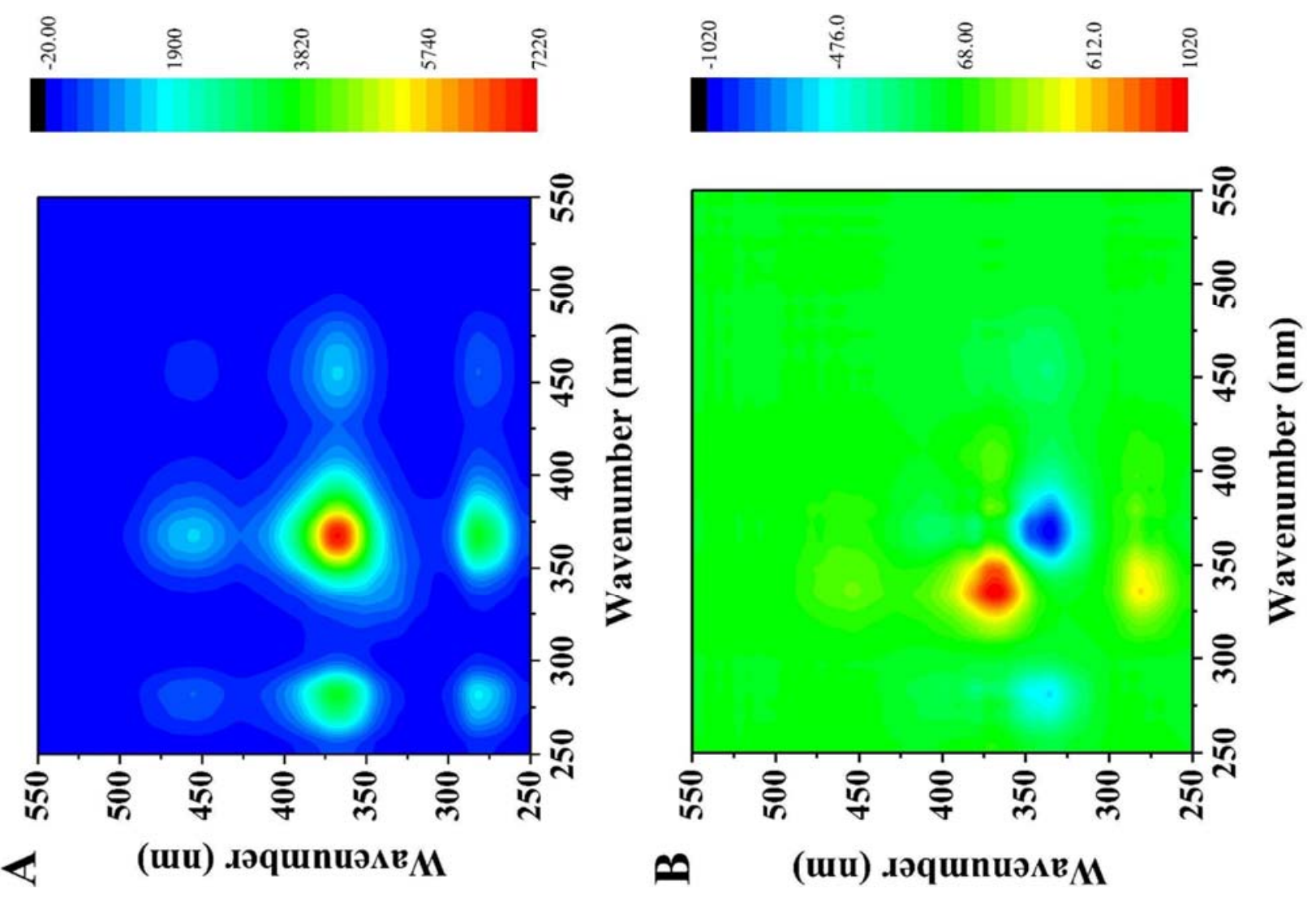

Fig. 7. 2D-COS maps for the synchronous fluorescence spectra of released SMPs as a function of reaction time: (A) synchronous map; (B) asynchronous map.

Correspondingly, the asynchronous map reveals the sequential or successive changes of spectral intensities in response to external perturbation [37]. As shown in Fig. 7B, one negative and two positive cross-peaks were observed above the diagonal line of the asynchronous map, centering at $281 / 336 \mathrm{~nm}, 336 / 453 \mathrm{~nm}$ and 336/367.5, respectively. Based on Noda's rule, the adsorption occurred sequentially in the order of $336>281,367.5$ and $453 \mathrm{~nm}$, suggesting that the fulvic-like fraction occurred earlier in metal exposure than the protein-like and humic-like fluorescence fractions. The result also demonstrated that the shorter wavelength $(336 \mathrm{~nm})$ was preferentially released earlier than longer wavelengths in the fulvic-like fluorescence fraction $(367.5 \mathrm{~nm})$.

\subsubsection{MW distribution}

To better understand the different size ranges of SMPs released from the biosorption process, the MW distribution of released SMP samples was evaluated at initial and final reaction times (5 and $330 \mathrm{~min}$ ). Fig. 8 shows that two obvious peaks were identified from SMP samples with MW of approximately 861 and $1480 \mathrm{Da}$ at the initial $5 \mathrm{~min}$. Afterwards, more MW peaks with higher values appeared at approximately 220, 400, 1000, 1841 and $2542 \mathrm{Da}$ at $330 \mathrm{~min}$. The low-MW organic matter smaller than 1000 Da may be attributed to the presence of carbohydrates, organic acids and amino acids, etc. [38] The higher-MW (1000-1200 Da) fraction at 330 min may due to 
the production of aromatic residues during the biosorption process (i.e., fulvic and humic acids), as similarly reported by Slomberg et al [39]. Therefore, the result of MW distribution implied that the released organic matter from the biosorption process was significantly different, depending on exposure time.

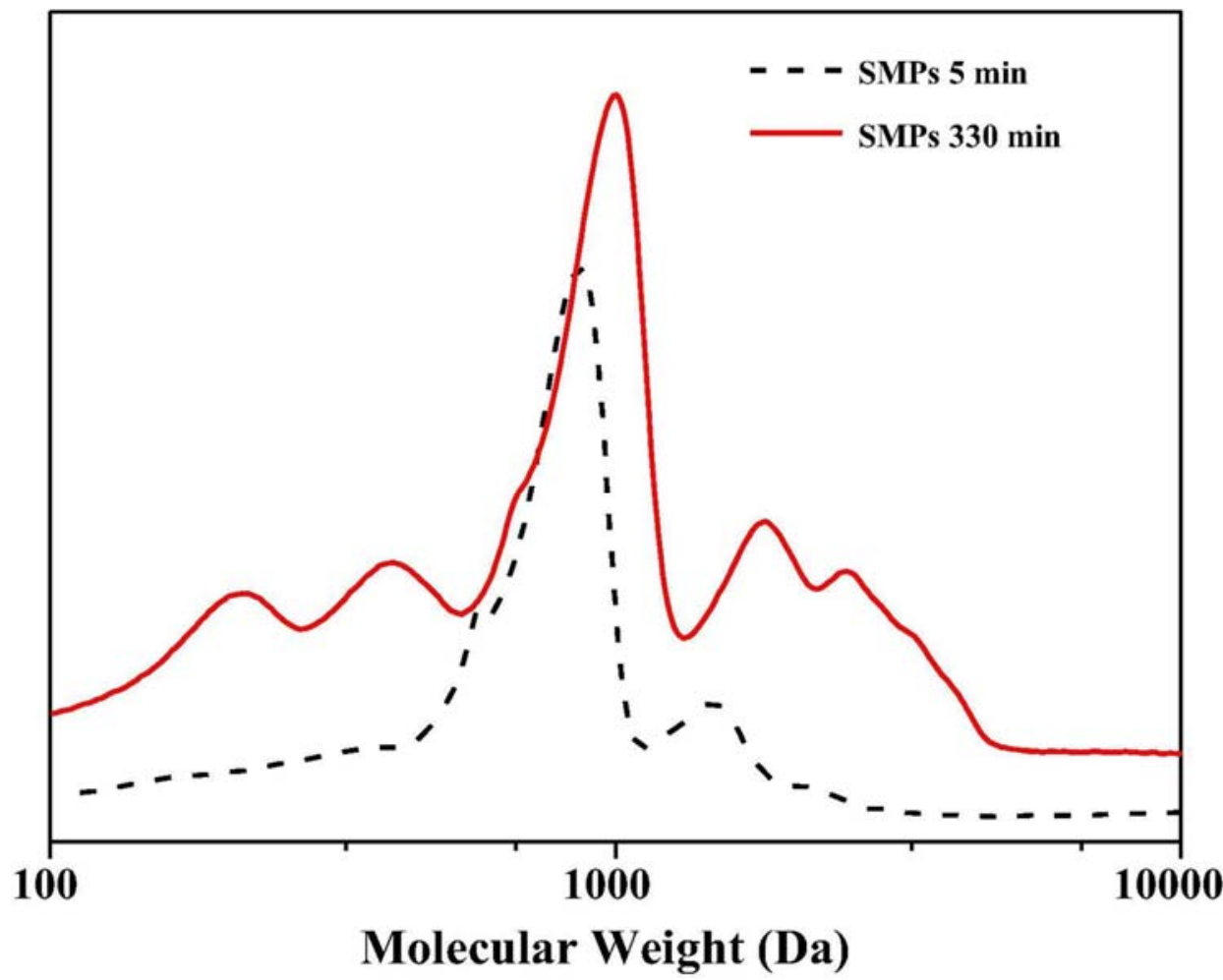

Fig. 8. Molecular weight distribution of SMPs samples released from biosorption process at initial and final reaction times (5 and $330 \mathrm{~min}$ ).

\section{Conclusions}

In summary, the results of the present study demonstrated that two kinds of microbial products (EPSs and SMPs) played different roles in the biosorption process of $\mathrm{Cu}$ (II) onto aerobic granular sludge. EPS binding was found to contribute to $\mathrm{Cu}(\mathrm{II})$ removal and was affected by contact time and influent metal concentrations. The interaction between EPSs and $\mathrm{Cu}$ (II) was caused mainly by tryptophan PN-like substances. In contrast, SMPs were simultaneous released with an increasing trend to contact time, which could be proved by using fluorescence spectra coupled to WM distribution. The result obtained could provide valuable information for understanding the responses of microbial products in the biosorption process of heavy metals onto sludge-based sorbents via a spectroscopic approach. Future investigations will be developed to reduce the SMP release simultaneously during the heavy metal biosorption process.

\section{Acknowledgements}

This study was supported by the Natural Science Foundation of Shandong Province (ZR201702070162), National Natural Science Foundation of China (21777056, 51508226), a Project of Shandong Province Higher Educational Science and Technology Program (J17KA191), 
and QW thanks the Special Foundation for the Taishan Scholar Professorship of Shandong Province and UJN (No. ts20130937).

\section{Appendix A. Supplementary material}

Supplementary data associated with this article can be found, in the online version, at https://doi.org/10.1016/j.jcis.2018.05.032.

\section{References}

[1] S. Yu, X. Wang, H. Pang, R. Zhang, W. Song, D. Fu, T. Hayat, X. Wang, S. Yu, X. Wang, Boron nitride-based materials for the removal of pollutants from aqueous solutions: a review, Chem. Eng. J. 333 (2018) 343-360.

[2] J. Wang, C. Chen, Biosorbents for heavy metals removal and their future, Biotechnol. Adv. 27 (2009) $195-226$.

[3] Y. Cai, C. Li, D. Wu, W. Wang, F. Tan, X. Wang, P.K. Wong, X. Qiao, Highly active MgO nanoparticles for simultaneous bacterial inactivation and heavy metal removal from aqueous solution, Chem. Eng. J. (2016) 158-166.

[4] G. Yan, T. Viraraghavan, Heavy-metal removal from aqueous solution by fungus Mucor rouxii, Water Res. 37 (2003) 4486-4496.

[5] T.A. Davis, B. Volesky, A. Mucci, A review of the biochemistry of heavy metal biosorption by brown algae, Water Res. 37 (2003) 4311-4330.

[6] C. Ding, W. Cheng, X. Wang, Z.Y. Wu, Y. Sun, C. Chen, X. Wang, S.H. Yu, Competitive sorption of $\mathrm{Pb}(\mathrm{II}), \mathrm{Cu}(\mathrm{II})$ and $\mathrm{Ni}(\mathrm{II})$ on carbonaceous nanofibers: A spectroscopic and modeling approach, J. Hazard Mater. 313 (2016) 253-261.

[7] B. Volesky, Biosorption and me, Water Res. 41 (2007) 4017-4029.

[8] M. Miao, Y. Wang, Q. Kong, L. Shu, Adsorption kinetics and optimum conditions for Cr(VI) removal by activated carbon prepared from luffa sponge, Desalin. Water Treat. 57 (2016) $7763-$ 7772.

[9] J. Zhao, J. Huang, M. Guan, Y. Zhao, G. Chen, X. Tian, Mathematical simulating the process of aerobic granular sludge treating high carbon and nitrogen concentration wastewater, Chem. Eng. J. 306 (2016) 676-684.

[10] Q. Kong, H.H. Ngo, L. Shu, R.S. Fu, C.H. Jiang, M.S. Miao, Enhancement of aerobic granulation by zero-valent iron in sequencing batch airlift reactor, J. Hazard Mater. 279 (2014) 511-517.

[11] X.F. Sun, Y. Ma, X.W. Liu, S.G. Wang, B.Y. Gao, X.M. Li, Sorption and detoxification of chromium (VI) by aerobic granules functionalized with polyethylenimine, Water Res. 44 (2010) 2517-2524.

[12] S.S. Adav, D.J. Lee, K.Y. Show, J.H. Tay, Aerobic granular sludge: recent advances, Biotechnol. Adv. 26 (2008) 411-423.

[13] T. Janus, B. Ulanicki, Modelling SMP and EPS formation and degradation kinetics with an extended ASM3 model, Desalination 261 (2010) 117-125.

[14] C.S. Laspidou, B.E. Rittmann, A unified theory for extracellular polymeric substances, soluble microbial products, and active and inert biomass, Water Res. 36 (2002) 2711-2720. 
[15] G.P. Sheng, H.Q. Yu, X.Y. Li, Extracellular polymeric substances (EPS) of microbial aggregates in biological wastewater treatment systems: a review, Biotechnol. Adv. 28 (2010) 882-894.

[16] Z. Zhang, Y. Zhou, J. Zhang, S. Xia, S.W. Hermanowicz, Effects of short-time aerobic digestion on extracellular polymeric substances and sludge features of waste activated sludge, Chem. Eng. J. 299 (2016) 177-183.

[17] W.W. Li, H.Q. Yu, Insight into the roles of microbial extracellular polymer substances in metal biosorption, Bioresource Technol. 160 (2013) 15-23.

[18] D. Wei, M.T. Li, X.D. Wang, F. Han, L.S. Li, J. Guo, L.J. Ai, L.L. Fang, L. Liu, B. Du, Extracellular polymeric substances for Zn (II) binding during its sorption process onto aerobic granular sludge, J. Hazard Mater. 301 (2016) 407-415.

[19] D.J. Barker, D.C. Stuckey, A review of soluble microbial products (SMP) in wastewater treatment system, Water Res. 33 (1999) 3063-3082.

[20] D. Wei, L. Shi, T. Yan, G. Zhang, Y. Wang, B. Du, Aerobic granules formation and simultaneous nitrogen and phosphorus removal treating high strength ammonia wastewater in sequencing batch reactor, Bioresource Technol. 171 (2014) 211-216.

[21] J. Xu, G.P. Sheng, Y. Ma, L.F. Wang, H.Q. Yu, Roles of extracellular polymeric substances (EPS) in the migration and removal of sulfamethazine in activated sludge system, Water Res. 47 (2013) 5298-5306.

[22] X.Y. Li, S.F. Yang, Influence of loosely bound extracellular polymeric substances (EPS) on the flocculation, sedimentation and dewaterability of activated sludge, Water Res. 41 (2007) 10221030 .

[23] I. Noda, Two-dimensional correlation spectroscopy: applications in vibrational and optical spectroscopy, Nova 77 (2004) 239-244.

[24] X. Li, Y. Liu, C. Zhang, T. Wen, L. Zhuang, X. Wang, G. Song, D. Chen, Y. Ai, T. Hayat, Porous $\mathrm{Fe} 2 \mathrm{O} 3$ microcubes derived from metal organic frameworks for efficient elimination of organic pollutants and heavy metal ions, Chem. Eng. J. (2017) 241-252.

[25] W. Yao, J. Wang, P. Wang, X. Wang, S. Yu, Y. Zou, J. Hou, T. Hayat, A. Alsaedi, X. Wang, Synergistic coagulation of GO and secondary adsorption of heavy metal ions on $\mathrm{Ca} / \mathrm{Al}$ layered double hydroxides, Environ. Pollut. 229 (2017) 827-836.

[26] Z. Wang, Z. Wu, S. Tang, Characterization of dissolved organic matter in a submerged membrane bioreactor by using three-dimensional excitation and emission matrix fluorescence spectroscopy, Water Res. 43 (2009) 1533-1540.

[27] D. Wei, B. Wang, H.H. Ngo, W. Guo, F. Han, X. Wang, B. Du, Q. Wei, Role of extracellular polymeric substances in biosorption of dye wastewater using aerobic granular sludge, Bioresource Technol. 185 (2015) 14-20.

[28] W. Chen, P. Westerhoff, J.A. Leenheer, K. Booksh, Fluorescence excitationemission matrix regional integration to quantify spectra for dissolved organic matter, Environ. Sci. Technol. 37 (2003) 5701-5710.

[29] C.A.M. Seidel, A.S. And, M.H.M. Sauer, Nucleobase-specific quenching of fluorescent dyes. 1. Nucleobase one-electron redox potentials and their correlation with static and dynamic quenching efficiencies, J. Phys. Chem. 100 (1996) 5541-5553.

[30] B. Pan, Y. Liu, D. Xiao, F. Wu, M. Wu, D. Zhang, B. Xing, Quantitative identification of dynamic and static quenching of ofloxacin by dissolved organic matter using temperature-dependent kinetic approach, Environ. Pollut. 161 (2012) 192-198. 
[31] F.J. Rodríguez, P. Schlenger, M. García-Valverde, A comprehensive structural evaluation of humic substances using several fluorescence techniques before and after ozonation. Part I: structural characterization of humic substances, Sci. Tot. Environ. 476 (2013) 718-730.

[32] W. Chen, N. Habibul, X.Y. Liu, G.P. Sheng, H.Q. Yu, Ftir and synchronous fluorescence heterospectral two-dimensional correlation analyses on the binding characteristics of copper onto dissolved organic matter, Environ. Sci. Technol. 49 (2015) 2052-2058.

[33] X. Guo, H. Yu, Z. Yan, H. Gao, Y. Zhang, Tracking variations of fluorescent dissolved organic matter during wastewater treatment by accumulative fluorescence emission spectroscopy combined with principal component, second derivative and canonical correlation analyses, Chemosphere 194 (2018) 463-470.

[34] J. Li, J. Wei, H.H. Ngo, W. Guo, H. Liu, B. Du, Q. Wei, D. Wei, Characterization of soluble microbial products in a partial nitrification sequencing batch biofilm reactor treating high ammonia nitrogen wastewater, Bioresource Technol. 249 (2018) 241-246.

[35] T.M. Lai, S. Jae-Ki, H. Jin, Estimating the biodegradability of treated sewage samples using synchronous fluorescence spectra, Sensors 11 (2011) 7382-7394.

[36] H. Xu, H. Jiang, UV-induced photochemical heterogeneity of dissolved and attached organic matter associated with cyanobacterial blooms in a eutrophic freshwater lake, Water Res. 47 (2013) 6506-6515.

[37] H. Jin, B.M. Lee, Characterization of binding site heterogeneity for copper within dissolved organic matter fractions using two-dimensional correlation fluorescence spectroscopy, Chemosphere 83 (2011) 1603-1611.

[38] H. Shon, S. Vigneswaran, S. Snyder, Effluent organic matter (EfOM) in wastewater: constituents, effects, and treatment, Crit. Rev. Environ. Sci. Techlol. 36 (2006) 327-374.

[39] D.L. Slomberg, P. Ollivier, O. Radakovitch, N. Baran, N. Sanikast, A. Bruchet, M. Scheringer, J. Labille, Insights into natural organic matter and pesticide characterisation and distribution in the Rhone River, Environ. Chem. 14 (2016) 64-73. 